\title{
Ethics behind Leadership in Different Economies
}

\author{
Jacques Touma \\ Lebanese American University, Byblos, Lebanon \\ Email: jacques.touma@lau.edu.lb
}

How to cite this paper: Touma, J. (2022). Ethics behind Leadership in Different Economies. American Journal of Industrial and Business Management, 12, 135-144. https://doi.org/10.4236/ajibm.2022.122009

Received: January 14, 2021

Accepted: February 14, 2022

Published: February 17, 2022

Copyright $\odot 2022$ by author(s) and Scientific Research Publishing Inc. This work is licensed under the Creative Commons Attribution International License (CC BY 4.0).

http://creativecommons.org/licenses/by/4.0/

\begin{abstract}
Leadership has been defined as a methodology of social influence in which one individual can engage the aid and the support of others in the achievement of a typical task. For instance, some comprehend a leader essentially as someone whom individuals take after or as someone who guides or motivates individuals, while others characterize leadership as "arranging a group of individuals to attain a typical objective and achieve mutual objectives". Leadership studies have created several types of theories including traits, function, power, situational interaction, vision, behavior, intelligence and charisma. For instance, the leadership Grid is a situational leadership which is based on two behavioral dimensions-concern for production, plotted on the X-axis on a scale from one to nine points; and concern for people, plotted on a similar scale along the Y-axis. The model proposes that the team leadership style, which displays a high degree of concern for both production and people, may boost employee productivity. This paper addresses Ethics in Leadership and how ethical and unethical leaders affect the performance of employees and addresses at the same time the impact of leadership behavior in different economics whether static or dynamic.
\end{abstract}

\section{Keywords}

Ethics, Leaders, Static, Dynamic, Different Economies

\section{Leadership with and through 0thers}

Leadership is the process of encouraging and motivating others to reach their goals. A leader is the person who influences the behavior of others and sets strategic plans leading to the growth and development of the organization.

A leader is ready to establish the vision, mission and growth; he should be proactive and able to set many choices and alternatives on the long-term. More- 
over, he should be able to inspire others to work together enthusiastically (Yammarino, 2013). An effective leader gives credit to the employee for a job well done and supports others that need help to reach their goals ultimately.

The leadership traits are important for solving problems properly, developing better policies for the institution, building teamwork and delegating tasks (Denehy, 2008). A good leader could identify his strengths and weaknesses and work best to improve the ways of thinking.

A leader should be trustworthy to the employees. It is expected from a good leader to make the good choices for the company without having to take part of any personal benefits. A leader should know everyone's role in the organization and what helps them to make their jobs satisfactorily. Being able to motivate and influence the employees in order to become more productive and make them believe in the organization's vision. A leader should have the drive to succeed in order to overcome the consequence that the company faces (Hunt, 2002). Believe that success is reached with the assistance of the whole team and enrich their minds through frequent training programs. A good leader treats all the team members equally with no discrimination, encourages employees working together as a team in order to reach the highest productivity possible and improve their morale. A leader encourages a healthy atmosphere where employees cooperate to solve work obstacles. The employee should feel that the leader is part of the team and has the authority to make decisions at same level.

On the other end, the perception of leadership and how it is communicated to people has placed the industry whether through educational centers, programs, conferences, etc. in a position that leaders can be developed easily, trained on how to become a leader or effectively how to lead better. Billions of dollars are spent yearly on leadership development and learning where some of the assumptions are that trainings and development would lead to effective people, ethical, and consequential (Kellerman, 2016).

\section{Ethical Leadership}

\subsection{Ethical Leadership and Its Impact}

"Ethics simply means what is right and wrong" but when discussing leadership and business ethics, what is right and wrong will be more related to decisions, regulations, policies and rules. Ethics will provide leaders guidelines to measure between their interests and responsibilities (Saeed et al., 2013). Studies have shown that when leaders encourage fair treatment and share values inside the organization, favorable behaviors will be spread among employees who will feel more committed and motivated (Piccolo et al., 2010).

Ethical leadership as defined by Brown et al. (2005) is "the demonstration of normatively appropriate conduct through personal actions and interpersonal relationships, and the promotion of such conduct to followers through two -way communication, reinforcement and decision-making". This definition describes the ethical leader as the person with "right values" and "strong character". More- 
over, Ethical leaders are the ones able to incorporate ethically the purpose, vision, values, and goals of the organization to meet the goals of the internal employees and external stakeholders (Piccolo et al., 2010). These leaders distinguish themselves by specific traits such as honesty, fairness, trustworthiness and their ability to make fair and balanced decisions.

O'Connell and Bligh (2009) identified the following nine characteristics of an ethical leader:

1) Uses an ethical "lens".

2) Makes ethical decisions.

3) Considers the long-term implications of business decisions.

4) Considers others when making decisions.

5) Acts like a role model behavior.

6) Spreads the importance of ethics.

7) Encourages others to act ethically.

8) Understands themselves and their environment.

9) Offers training to their employees to encourage them to act ethically.

These above qualities will make a leader unique and will have a direct influence on the employees' performance, motivation, and turnover intention inside the organization.

Ethical leadership implementation addresses all sectors and according to Pfaff (2019) in his research regarding "the ethics of acquiring disruptive technologies", leaders in military should take ethics in consideration when they look at the gap responsibilities of creating Artificial Intelligence weapons where operators need to ensure these machines are built to perform ethically and communicate the ethical framework to the public.

In addition to the above, artificial intelligence and emerging technologies would lead to the creation of legal and ethical standards but the question remains under what speed. Customer safety and privacy for instance are topics to be included in the way the common approach is going to be handled not to mention the necessity to involve many stakeholders such as government regulators, NGOs, Human rights groups, private sector to name a few (Allen et al., 2020).

\subsection{Ethical Leadership and Employees' Job Performance}

The goals and objectives of the organizations can not be reached without the employees who are considered as the most important assets inside the organizations. Therefore, ethical leadership can be very effective to increase employees' satisfaction and performance.

In fact, leaders who create ethical environment inside their companies are characterized by their ethical awareness and concern for their employees'. They will consider more the needs of their employees and they will treat them fairly. Therefore, these leaders will be perceived as model inside the company and the employees will start having strong appreciation for the top management (Gha- 
hroodi et al., 2010). They will start showing more willingness to put extra effort on task performance. As a result of improving performance in ethical leadership organization, trust and commitment will increase too and protect long-term performance of the firm.

Studies have shown that the more company climate is perceived as ethical, the more the employee's trust will be, creating more efficient relationships between managers, employees, and top managers. As a result, employees will show more compliance to the internal rules and implementation of changes inside the organization will be easier (Bello, 2012).

Commitment is defined as the loyalty and attachment of the employee to the organization. Positive relation is obvious between the impact of the leader's ethical behavior and employee commitment to the organization leading to improve quality of products and increase loyalty (Mize et al., 2000).

\subsection{Ethical Leadership and Employees' Motivation}

Ethical leaders encourage communication with their followers, give them a chance to express themselves, and encourage them to be a part of the decision making (Piccolo et al., 2010). They have the "power of sharing" and the ability to listen to their employees' ideas and concerns. "Power Sharing" will make the employee inside the organizations more responsible and less dependent on their leaders. This greater sense of trust and control will lead to a more personal responsibility and usually it is shown by a greater sense of "Motivation". Moreover, leaders started to use the reward system to motivate their employees and make them responsible for their own work. They used reinforcement to reward the employees for their ethical behaviors and punishment for the employees who failed to consider the negative impact of their decisions on the work team and employees inside the organization. By adding rewards and punishment to ethical behavior, employees will feel more motivated to meet the organizational goals in an ethical way.

\subsection{Ethical Leadership and Turnover Intention}

Researchers have found important relationship between ethical relationship and many organizational outcomes. By studying different types of organizations in the USA, Mayer et al. (2009) found that top managers ethical leadership can be transmitted to middle managers and it can affect positively all employees inside the organization. It depends on the nature of the company and how leaders want to achieve their goals. Moreover, Ruiz-Palomino et al. (2011) declared that there is significant relationship between supervisors' ethical leadership, employees' commitment and job satisfaction which will directly affect the turnover intention.

Being committed to organization will reflect how the employee is attached to the workplace, or the organization, and the amount of willingness to evolve and participate. This implies that when the employee is happy at the workplace, the intention of leaving the organization will be diminished. Leaders should take in- 
to consideration that when intention to change job is reduced then they will avoid additional costs such as trainings and recruitments.

Being an ethical leader model can increase job satisfaction and organizational commitment as the outcomes variable of this leadership style, followers will enjoy being effective to their jobs, therefore their intention to change will be reduced.

According to Mango (2018), it is essential to shed the light on the followers and if they are knowledgeable about a subject matter more than the leader, then it is crucial to take the lead at that particular case. Leaders must know their followers and sense the fact of how much they are willing to act on the tasks to deliver the job well done.

\subsection{Ethical Leadership and Effectiveness}

In History, successful leaders were defined by their ability to bring change whether for good or worse. In all definitions stated above a good leader is an ethical and effective leader (Ciulla, 2003), but the problem is that sometimes we do not find effectiveness and ethics in the same leader. Some leaders are highly ethical but not very effective. In addition, we can find highly successful leaders serving the needs of their organizations but not in a very ethical way. In some situations, it is essential to differentiate between ethics and effectiveness where being effective will make a leader ethical or vice versa. Some leaders worked ethically but in many cases they failed and created negative outcomes.

In the context of ethics and effectiveness issue, some theories have declared that the "Intention" of the leader is the most important aspect to work ethically and being effective. So, if the leader is working according to his duties and morals than he is being ethical regarding the outcomes. However, others declared that the ethic of an action is in its result. In fact, both theories are needed to have an ethical and effective leader at the same time, so a good leader should work according to his duties, morals and should keep the notion of the great outcomes always in mind (Ciulla, 2003).

\section{Leadership Challenges in Static versus Dynamic Economy}

Research shows that subordinates perceive their leaders differently in different places depending on the economy which constitutes the financial power a leader might have in additional to other factors such as culture for instance. For the sake of argument, this part of the paper uses the model of Hofstede and its cross-cultural elements when addressing power distance while comparing results in both economies.

A study was conducted part of a research dissertation at the University of Phoenix showing difference on how leaders are perceived in both economies (Lebanon and USA). According to the study which was piloted in the field of banking sector revealed that subordinates in Lebanon were more geared toward initiation structure, a society with high power distance and surprisingly lower masculinity while subordinates in the USA are more geared towards considera- 
tion, a society with lower power distance and surprisingly higher masculinity (Oueini, 2005).

In a static economy and because of its financial implications, the leader's role shifts to adopt, enrich internal corporate environment and substitute what usually is given in a dynamic economy. Additional efforts need to be put in place such as safety, quality procedures, and corporate policies when certain things are not mandated by law like retirement for elderly, age discrimination, sexual discrimination and so forth. In a dynamic economy, the leader's role is more to ensure the practice of good ethics where the society in general is aware of norms, standards and practices.

In Lebanon it appears that the results showed a low masculinity index in the banking sector which is usually present in an open society and unlike the rest of the study showing Lebanon as a traditional society rather than open. This means even in a static economy a presence of some deviation in particular sector might occur.

The research concluded that there was statistical significance between both economies where in Lebanon the society was less employee oriented and more task oriented and power is in the hands of few aiming to have equality among population rather than freedom. On the other hand, the U.S. promotes changes through the redistribution of power and low power distance encouraging high participation of subordinates in decision making leading to better overall performance thus higher financial turnover, EBITA growth, satisfaction of stakeholders and healthier economic development.

\subsection{Gender Leadership in Different Economies}

Gender plays also an important role in corporate leadership for instance according to the latest statistics by the US labor of statistics (December 2020, study results 2019) that women get paid 82 percent on the dollar compared to men. Studies also show that women in leadership position tend to be more relationship oriented and engage in consideration behavior whereas men are more task oriented and engage in more structure behavior. Women tend to be more participative involving subordinates in decision making. Men tend to be harsher when punishing subordinates than women. Besides the different economies, women in general usually face many common constraints and according to some qualitative research, findings reported by Lebanese women are similar to the ones worldwide where the variation remains in different stream of culture and expectation of traditional women role. According to Damousi and Tomsic (2014), whether men or women who hold the position of leadership, it all depends on the style of leadership they practice in addition to how they are presented, understood by their employees.

\subsection{Economic Market Adaptation by Leaders}

Economy plays a big role on the effectiveness of leadership. A leader must have 
the ability to exercise the reward power along with all other power. Compensation makes the employee happy, it satisfies the needs and in a dynamic environment once the physiological needs are satisfied, it is only human nature to start looking towards terminal values. Things are not the same in a different economy, for instance in a static economy where the employee is barely satisfying the basic needs, the expectancy theory of motivation still remains valid where effort are put to reach performance which ultimately leads to an outcome thus that outcome could be extrinsic or intrinsic but the fact of the matter is any compensation that is not extrinsic could be very hard for the leader to implement and sustain the level of motivation needed from that employee. In the effort to exercise ethics and social responsibilities, there are many strategic positioning leaders may choose for their company. Usually in less developed countries, leaders may take advantage of the flaws in the system and in case these markets are static and have economic problems, leaders may choose the strategy of obstructionist positioning which is in principle not ethical and not legal in some cases. Although this positioning could be present even in well developed countries but on a smaller scale due to the restriction and systematic integration throughout the process of business interaction with government and other entities imposing certain procedural regulations.

An accommodative strategy may be adapted by leaders in cases where research and development is not efficient coupled with a large market size. Leaders may choose the predation strategy with the aim to attain a monopoly positioning after a certain time. Leaders would be willing to incur losses at first to reach that time and in a dynamic economy unlike the static one, this could last until that desired time is reached. Once predation strategy is at optimal level, leaders invest heavily in research and development to speed up the process and reach the desired time forcing all other firms or followers to exit. At that point the company practices Monopoly (Kovac et al., 2010).

\section{Findings}

There are key elements that need to be addressed when analyzing the positioning of self and the opportunity to advance on the corporate ladder, they are as follows:

- The economy in place whether static or dynamic and that could determine the limitation of corporate practices.

- The size of the economic market and the size of the company of interest.

- The company strategic positioning among others in the field.

- Leadership style, type, behavior, traits associated in the company of interest.

- The effectiveness of the leadership style and internal environment.

- The practices of ethics, social responsibilities and inputs on cross-cultural model presence.

Below are two strategies that may help employees to deal and absorb their leader: 
- The better you comprehend what your manager does and more significantly, why, the better situated you are to convey results, oversee desires, and maintain a strategic distance from lose/lose circumstances. Attempt to place yourself in their shoes and see the world, and your work environment, as they may.

When you recognize what drives your manager, regardless of the fact that your manager may not be completely aware of it, edge your presumptions and use dialect in ways that line up with your leader's values, priorities and concerns.

Unethical behavior among followers can be particularly destructive to the organization or association they lead, as it is basic for a whole association to tackle the identity and behavioral standard of their leader. Consequently, while unethical behavior at any level brings about unfavorable results for an organization or company, the most breathtaking goes wrong accompany their CEO or other dignitary acting unethically.

There are many types of leaders and some of them are successful in reaching personal and corporate goals, increasing profit and revenue through high performance, efficiency and effectiveness of operations but the fact of the matter is how ethical their practices are in terms of reaching successful records. Some leaders practice camouflaged aggression to get to their goal maybe by eliminating a competitive resource or they practice the Machiavelli's approach where "the end justifies the means" but in all cases economic and capital gains only do not make a leader beautiful in the eyes of the people (subordinates) but rather the leader's honesty, transparency, effectiveness, confidence, fairness, and guidance.

\section{Conclusion}

Unethical behavior can be any activity or game plan that the general public or the organization sees as being less than acceptable. From the highest point of an association to the lowliest step of the professional level, unethical behavior has a method for disintegrating an organization's activities; bringing down the quality and nature of work; and inevitably prompting the organization's provisional, or even changeless, downfall.

Great leadership is essential to make a business flourish and develop. The most effective approach to deal with staff or group is by creating every part of the group through instructing and open communication. The result could be astonishing from productivity perspective when the leader develops a small group of solid and effective employees at a sensible rate of pay rather than utilizes a large group or team of immature laborers for low pay; however numerous organizations are constrained into the last as a result of ineffective leadership.

Leaders get a significant part of the credit for achievement and furthermore bear the majority of the fault for ethical disappointments and failures in companies. Given their obvious positions of power, authority, obligation regarding 
molding formal authoritative strategies, progressing interactions with the followers, and control over essential prizes and disciplines, leaders ought to assume a critical part in impacting workers' ethical and unethical behavior.

Through demonstrating, leaders impact followers by showing high ethical measures in their own particular behavior and by utilizing the reward system to show the followers vicariously about the conclusions of ethical and unethical conduct in the company.

Moreover, leaders who are seen as reliable and trustworthy, and who treat their followers fairly, decently and accommodatingly, will create social trade relationships that bring about workers responding in positive ways.

Leadership is immensely critical, important and merits more consideration in our endeavors to comprehend employee ethical behavior and unethical behavior. On the other hand, we ought to additionally put the part of leaders in a more extensive setting and comprehend its potential limitations.

This paper addressed how ethical and unethical leaders affect the performance of employees but the main contribution of this paper, it covered both static and dynamic economics and ultimately pin-pointed on the effectiveness of leadership in both considering internal and external factors.

\section{Limitation}

This paper addressed Ethics behind leadership and its implications in different economies. A limiting factor of approaching employees during the pandemic was a common excuse that most of them were overwhelmed which affected the speed and time taken to conduct the study. In addition, due to covid-19, two interviews were conducted exceptionally using online platform to wrap up the research therefore had some internet connection issues that took more time than expected.

\section{Conflicts of Interest}

The author declares no conflicts of interest regarding the publication of this paper.

\section{References}

Allen, G. J., Déau, T., Donfried, K., Froman, M., Ashton, B. C., Dębski, S., Enderlein, H., Hurd, W., Ischinger, W., Maigre, M., Manyika, J., Slotkin, E., Lajčák, M., Malmström, C., \& Schake, K. (2020). Technological Leadership. In G. J. Allen et al. (Eds.), Choices and Strategies for Transatlantic Relations for 2021 and Beyond (pp. 30-33). German Marshall Fund of the United States. http://www.jstor.org/stable/resrep27629.9

Bello, S. M. (2012). Impact of Ethical Leadership on Employee Job Performance. International Journal of Business and Social Science, 3, 228-235.

Brown, M. E., Trevino, L. K., \& Harrison, D. A. (2005). Ethical Leadership: A Social Learning Perspective for Construct Development and Testing. Organizational Human Behavior and Human Decision Processes, 97, 117-134. https://doi.org/10.1016/j.obhdp.2005.03.002 
Ciulla, J. (2003). Ethics and Leadership Effectiveness. In Emerging Issues in LeadershipCulture, Gender, and Ethics (pp. 302-307). Springer Link.

Damousi, J., \& Tomsic, M. (2014). Conclusion: Gender and Leadership. In J. Damousi, M. Tomsic, \& K. Rubenstein (Eds.), Diversity in Leadership: Australian Women, Past and Present (pp. 331-334). ANU Press. http://www.jstor.org/stable/j.ctt13wwvj5.21 https://doi.org/10.22459/DL.11.2014.18

Denehy, J. (2008). Leadership Characteristics. The Journal of School Nursing, 24, 107-110. https://doi.org/10.1177/1059840512341234

Ghahroodi, H. K., Ghazali, M., \& Ghorban, Z. S. (2010). Examining Ethical Behavior and Its Impacts on the Followers' Behavioral Outcomes. Asian Social Science, 9, 91-96. https://doi.org/10.5539/ass.v9n3p91

Hunt, J. (2002). Leadership Traits That Increase a Leader's Effectiveness. https://smallbusiness.chron.com/honesty-important-business-22624.html

Kellerman, B. (2016). Leadership-It's a System, Not a Person! Daedalus, 145, 83-94. http://www.jstor.org/stable/24916690 https://doi.org/10.1162/DAED a 00399

Kovac, E., Vinogradov, V., \& Zigic, K. (2010). Technological Leadership and Persistence of Monopoly under Endogenous Entry: Static versus Dynamic Analysis. https://doi.org/10.2139/ssrn.1535675

Mango, E. (2018) Rethinking Leadership Theories. Open Journal of Leadership, 7, 57-88. https://doi.org/10.4236/oj1.2018.71005

Mayer, D., Kuenzi, M., Greenbbaum, R., Bardes, M., \& Selvador, R. (2009). How Low Does Ethical Leadership Flow? Test of a Trickle-Down Model. Organizational Behavior and Human Decision Processes, 108, 1-13. https://doi.org/10.1016/j.obhdp.2008.04.002

Mize, K. J., Stanforth, N., \& Johnson, C. (2000). Perception of Retail Supervisors' Ethical Organizational Commitment. Clothing and Textile Research Journal, 18, 100-110. https://doi.org/10.1177/0887302X0001800204

O’Connell, W., \& Bligh, M. (2009). Emerging for Ethical Scandal: Can Corruption Really Have a Happy Ending. Leadership, 5, 213-235. https://doi.org/10.1177/1742715009102935

Oueini, W. (2005). A Cultural Perspective of Subordinates' Perceptions of Leadership Style in Lebanese and United States Banking Industries. University of Phoenix, ProQuest, UMI Dissertations Publishing.

Pfaff, C. A. (2019). The Ethics of Acquiring Disruptive Technologies: Artificial Intelligence, Autonomous Weapons, and Decision Support Systems. PRISM, 8, 128-145. https://www.jstor.org/stable/26864280

Piccolo, R. F., Greembaum, R., Den Hartog, D. N., \& Folger, R. (2010). The Relationship between Ethical Leadership and Core Job Characteristics. Journal of Organizational Behavior, 31, 259-278. https://doi.org/10.1002/job.627

Ruiz-Palomino, P., Ruiz-Amaya, C., \& Knorr, H. (2011). Employee Organizational Citizenship Behavior: The Direct and Indirect Impact of Ethical Leadership. Canadian Journal of Administrative Sciences, 28, 244-258. https://doi.org/10.1002/cjas.221

Saeed, R., Sakeel, M., \& Lodi, R. N. (2013). Ethical Behavior and Employees Job Performance in Education Sector of Pakistan. Middle-East Journal of Scientific Research, 18, 524-529.

Yammarino, F. (2013). Leadership: Past, Present, and Future. Journal of Leadership \& Organizational Studies, 20, 149-155. https://doi.org/10.1177/1548051812471559 